\title{
The Clinical and Electrophysiological Features in Patients with Wolff-Parkinson- White Syndrome
}

\author{
Murari Dhungana*, Sujeeb Rajbhandari, Kunal Bikram Shaha, \\ Mukunda Sharma, Man Bahadur KC \\ Department of cardiology, \\ Shahid Gangalal National Heart Centre, Bansbari, Kathmandu, Nepal
}

\begin{abstract}
Citation
Dhungana M, Rajbhandari S, Shaha KB, et al. The Clinical and Electropysiological Features in Patients with Wolff-Parkinson-White Syndrome. Nepalese Heart Journal 2013;10(1):17-19.
\end{abstract}

Keywords

pre-excitation syndromes, Radiofrequency ablation, Wolff-Parkinson-White syndrome, Radiofrequency ablation

\begin{abstract}
Background and Aims: Wolff-Parkinson-White Syndrome is a congenital anomaly with delta wave in electrocardiogram representing an accessory conducting pathway. The aim of the present study was to evaluate the characteristic features of patients who underwent electrophysiological study and radiofrequency ablation at Shahid Gangalal National Heart Centre.
\end{abstract}

Methods: One hundred ninety eight patients with Wolff-Parkinson-White syndrome were divided in to three age groups; 1) 8 to 17,2$) 18$ to 29 and 3) 30 to 70 years. The clinical, electrophysiological and therapeutic data of these patients were taken retrospectively from the hospital records.

Result: A total of 10 (5\%) of these patients were less than 18 years of age. There was no sex difference in group 1 and 2. There were significantly more male patients in group 3. There were fewer patients with left sided accessory pathway in group 1 compared to group 2 and 3 ( $p=0.024$ and $p=0.002$, respectively).

Conclusion: This study describes several different electrophysiological characteristics in patients with Wolff-Parkinson-White syndrome. The study showed that the detection of left side accessory pathway was less frequent in children and adolescents with Wolff-Parkinson- White syndrome as well as no gender preponderance in this age group.

in individuals whose accessory pathway (AP) shows a short anterograde refractory period ${ }^{3}$, although the frequency of SCD is low $(0.3 \%))^{4,5}$ Radiofrequency ablation (RFA) of the AP is safe procedure and provides a 'cure' in most of the patients ${ }^{6}$. Recent studies have described the use

\section{${ }^{\star}$ Corresponding author:}

Murari Dhungana

Department of cardiology

Shahid Gangalal National Heart Centre,

Bansbari, Kathmandu, Nepal

Email: murarid@yahoo.com
WPW syndrome presents the risk of sudden cardiac death (SCD) from ventricular fibrillation 
of electrophysiological studies (EPS) for the risk stratification in asymptomatic WPW patients, and have emphasized that the findings, such as, the location and numbers of APs, which should be considered during a procedure involving $\mathrm{RFA}^{7}$. The clinical and electrophysiological characteristics of subjects with WPW syndrome may vary according to age ${ }^{8}$. The aim of the present study was to evaluate the characteristics of EPS and RFA performed in subjects with WPW syndrome at our centre.

\section{METHODS}

It is a retrospective study. One hundred and ninety eight patients with WPW with the age ranging from 8 to 70 years, who underwent EPS and RFA from April 2008 to April 2013 in Shahid Gangalal National Heart Centre, Kathmandu were included in this study.

Patients were divided into three age groups group 1, 8 to 17 years, group 2, 18 to 29 years, and group 3, 30 to 70 years. The indication for EPS was: 1) WPW patients with suspected or documented tachycardia, 2) In asymptomatic WPW patients aged less than 40 years or if the patient desired EPS and RFA. The location of the AP was confirmed during EPS using standard electrophysiological mapping methods. The EP system used was Biosense Webster's EP tracer with Stockert EP shuttle ablator and Saint Judes EP workmate with IBI-1500 T11 cardiac ablation generator.Tachycardia was induced by burst or continuous Atrial (A) pacing, Ventricular (V) pacing, or extrastimulus technique. After the location of the AP, radiofrequency energy was applied for at least one minute, if the pre excitation disappeared or there was change in retrograde conduction during $\mathrm{V}$ pacing. Acute success of RFA was considered if antegrade conduction through AP during atrial pacing or retrograde conduction during ventricular pacing did not recur for at least 30 minutes after the RFA.

\section{Statistical analysis}

Statistical analysis was performed. The Chi-square test was used to compare clinical and electrophysiological data. $p$ value of $<0.05$ was considered statistically significant.

\section{RESULTS}

In our study 67 patients (33\%) were less than30 years of age, and 161 were more than 30 years.

Group 1 consisted of five boys and five girls, group 2 consisted of 29 men and 28 women, and group 3 consisted of 71 men and 60 women. There was no gender preponderance in group 1 and 2 whereas male preponderance was noted in group 3 .

In group 1, none had congenital heart disease. In group 2, one had Ebstein anomaly and in group 3, two had Ebstein and two had Persistent Left Superior Venacava (PLSVC).

\section{Characteristics of the cases $(n=198)$}

\begin{tabular}{|c|c|c|c|}
\hline Age group & $\begin{array}{c}8-17 \\
\text { year s }\end{array}$ & $\begin{array}{l}18-29 \\
\text { years }\end{array}$ & $\begin{array}{l}30-70 \\
\text { years }\end{array}$ \\
\hline Male & $5(50 \%)$ & $29(50.8 \%)$ & $71(54.1 \%)$ \\
\hline Female & $5(50 \%)$ & $28(49.2 \%)$ & $60(45.9 \%)$ \\
\hline Multiple AP & 0 & 0 & 3 \\
\hline Parahisian AP & 0 & $4(66.6 \%)$ & $2(33.4 \%)$ \\
\hline $\begin{array}{l}\text { Congenital } \\
\text { Heart Disease }\end{array}$ & 0 & $1(20 \%)$ & $4(80 \%)$ \\
\hline \multicolumn{4}{|c|}{ Pathway } \\
\hline Left sided & $2(20 \%)$ & $30(52.7 \%)$ & $69(52.6 \%)$ \\
\hline Right sided & $8(80 \%)$ & $27(47.3 \%)$ & $62(47.4 \%)$ \\
\hline
\end{tabular}

\section{Electrophysiological data}

Regarding EPS findings, there was spontaneous atrial fibrillation (AF) induction in 5 patients in group of more than 30 years age and none in patients less than 30 years age. AF induction during EPS was more frequent in group $3(5 / 131)$ than in group 1 $(0 / 10)$ or in group $2(0 / 57)$.

Left sided AP was detected more frequently in group $2(30 / 57)$ and in group $3(69 / 131)$ than in group 1 $(2 / 10)(p=0.024, p=0.002$, respectively). However, no significant difference was found between groups 2 and $3(p=0.732)$.

Multiple AP was detected in three patients ( 0 in group 1,0 in group 2, and 3 in group 3.The incidence of multiple AP was not significantly different between patients more than 30 years age and less than 30 years age, and was also not significantly different between the groups.

The Parahisian AP, which is known to be associated with the risk of complete atrioventricular block, was detected in 6 patients ( 0 in group 1, 3 in group 2, and 3 in group 3). The incidence of Parahisian AP was not significantly different between the groups (group 1 vs. group 2, $\mathrm{p}=0.545$; group 2 vs. group 3, $\mathrm{p}=1.000$; group 1 vs. group $3, \mathrm{p}=0.41$ ).

Ablation failure occurred in 10 patients (4 of group 1, 3 of group 2, 3 of group 3).

\section{DISCUSSION}

In our study, the characteristic features of patients with WPW syndrome were; 1) no gender preponderance in lower age groups (1 and2) and 2) less incidence of left sided AP in group 1 than in any other age group.

Our study showed lower incidence of inducible AF during EPS in younger age patients, although these 
did not differ significantly from that observed in adults.

In addition, the present study showed that the presence of left side AP was less in children and adolescents with WPW syndrome. A previous study on elderly patients with WPW syndrome revealed that left lateral AP was more frequent and AF was induced more in older patients (more than 60 years of age) $)^{9}$. Our study also showed similar results, that is, left AP was more frequent in patients more than 18 years age $(99 / 188)$ than less than 18 years age $(2 / 10)$. The incidence of Parahisian AP was not found to differ significantly with age. The significance of this pathway is that during ablation there is significant risk of complete heart block (CHB). There was single incidence of $\mathrm{CHB}$ during ablation in our study.

In the present study, no patient in group 1 had congenital heart disease, but adults (group 2 and 3) had 5. Out of these five, 3 patients had Ebstein anomaly with right side AP and 2 patients had PLSVC.

Among the patient with ablation failure, most cases in our study had right sided AP and Parahisian
AP. For right sided AP, due to the structure of the tricuspid annulus, it is difficult to steady the tip of the ablation catheter over the annular portion during radiofrequency current application as steadily during RFA of a left sided AP. Therefore, RFA of right side AP requires more radiofrequency current application than left side AP and the process is more frequently interrupted ${ }^{10}$.

The limitations of the study are it is a single centre study with no follow up. Furthermore, we need to perform longer term follow up on our patients and to study changes in the characteristics of AP by age.

\section{CONCLUSION}

Our study describes several electrophysiological characteristics in patients with WPW syndrome. We noticed no gender preponderances in the lower age groups. Detection of left side AP was less frequent in children and adolescents with WPW syndrome. Fewer incidence of complication was noticed; therefore we can conclude that RFA is a safe and a reliable method of treatment for patients with WPW.

\section{REFERENCES}

1. Lundberg A. Paroxysmal tachycardia in infancy: follow-up study of 47 subjects ranging in age from 10 to 26 years. Pediatrics. 1973;51:26-35.

2. Sano S, Komori S, Amano T, Kohno I, Ishihara T, Sawanobori T, et al. Prevalence of ventricular preexcitation in Japanese schoolchildren. Heart. 1998;79:374-378.

3. Klein GJ, Bashore TM, Sellers TD, Pritchett EL, Smith WM, Gallagher JJ. Ventricular fibrillation in the Wolff-Parkinson-White Syndrome. N Engl J Med. 1979;301:10801085.

4. Timmermans C, Smeets JL, Rodriguez LM, Vrouchos G, van den Dool A, Wellens HJ. Aborted sudden death in the Wolff-ParkinsonWhite Syndrome. Am J Cardiol. 1995;76:492494.

5. Montoya PT, Brugada P, Smeets J, Talajic M, Della Bella P, Lezaun R, et al. Ventricular fibrillation in the Wolff-Parkinson-White syndrome. Eur Heart J. 1991;12:144-150.

6. Kuck KH, Schülter M, Geiger M, Siebels J, Duckeck W. Radiofrequency current catheter ablation of accessory atrioventricular pathways. Lancet. 1991;337:1557-1561.

7. Pappone C, Manguso F, Santinelli R, Vicedomini G, Sala S, Paglino G, et al. Radiofrequency ablation in children with asymptomatic WolffParkinson-White syndrome. N Engl J Med. 2004;351:1197-1205.

8. Michelucci A, Padeletti L, Mezzani A, Giovannini T, Miceli M, Cupelli V, et al. Relationship between age and anterograde refractoriness of the accessory pathway in Wolff-Parkinson-White patients. Cardiology. 1989;76:270-273.

9. Brembilla-Perrot B, YangniN'da O, Huttin O, Chometon F, Groben L, Christophe C, et al. Wolff-Parkinson-White syndrome in the elderly: clinical and electrophysiological findings. Arch Cardiovasc Dis. 2008;101:18-22.

10. Hae jung jung, Huang Young Ju, Myung Chul Hyun, Sang Bum Lee, Yeo Hyang Kim. Wolff-Parkinson- White Syndrome in young people, from childhood to young adulthood: relationships between age and clinical and electrophysiological findings. Korean j pediatric. 2011; 54: 507-511. 